\title{
An algorithm for the clinical assessment of nutritional status in hospitalized patients
}

\author{
J. Th. C. M. de Kruif and A. Vos* \\ University Medical Centre Utrecht, Department of Surgery, P.O. Box 85500, 3505 GA Utrecht, The Netherlands
}

(Received 22 November 2002 - Revised 12 May 2003 - Accepted 11 June 2003)

\begin{abstract}
Upon admission to hospital, 30-50\% of patients either are or become malnourished. There is no generally accepted definition of malnutrition or guidelines on the best way to establish nutritional status. We consider it self-evident that the nursing staff have an important role in screening patients at risk of malnutrition on admission and thereafter at regular times. This is why we developed the nursing nutritional screening form (NNSF). The NNSF was tested by nurses, dietitians and clinicians, in pairs, to establish the extent of agreement in two phases on sixty-nine and forty patients. Later, the form was used in practice by nursing staff on five wards (334 patients). Based on the results of the NNSF, patients were referred to a dietitian. The dietitian established whether the patient was indeed at risk, or was actually malnourished, using a complete nutritional history. The degree of concurrence within pairs was reasonable to good. The same applied to the concurrence between nursing staff and dietitians, but concurrence between clinicians and nursing staff was less. In total, 334 patients were screened and sixty-nine of them were referred to the dietitian. It was established that $86 \%$ of the referred patients were potentially at risk of malnutrition or were malnourished. Without the NNSF, $39 \%(n 27)$ of the patients referred to the dietitian would not have been referred, or would have been referred much later. The NNSF makes it possible for nurses to detect malnourished patients or patients at risk of malnutrition at an early stage of their hospitalization.
\end{abstract}

Malnutrition: Screening: Nursing: Consultation

Upon admission to a hospital, an estimated $30-50 \%$ of patients are either malnourished or will become malnourished (Kovacevich et al. 1997; Naber et al. 1997; Symreng et al. 1983; Kern \& Norton 1988). Malnutrition is associated with an increased risk of complications following surgery and medical treatment, an increase in recovery time and, as a consequence, longer hospitalization (Meyenfeldt et al. 1992; Edington et al. 2000). Therefore, identifying the onset of malnutrition is extremely important for the patient.

However, there is neither a good definition of malnutrition nor a sensitive method for detecting it (Naber et al. 1997; Halsted, 2001). The most commonly applied clinical definition is an unintentional weight loss of at least $10 \%$ in 3-6 months (Markou et al. 1993; McWhirter \& Pennington 1994; Bokhorst-de van der Schueren et al. 1997; Halsted, 2001). There are two methods available for nutritional assessment. The first is measuring body components, such as BMI, upper-arm anthropometry (skinfold-thickness measurements) creatinine/height index, serum albumin, transferring and pre-albumin and the total number of lymphocytes in blood, as well as $\mathrm{N}$ level and immune status (Collins et al. 1979; Forse \& Shizgal, 1980; Baker et al. 1982; Jong de et al. 1985; Edes, 1991; Klein et al. 1997) These methods are not particularly sensitive or specific, the range of what is normal is extremely wide and they are influenced by the nature, length and seriousness of the various diseases. Besides that, these variables are a snapshot in time and therefore not able to predict future development. There is neither conformity in the literature nor consensus as to which variables or combination of variables can best be applied to determine nutritional status (Blackburn \& Thornton, 1979; Collins et al. 1979; Buzby et al. 1980; Forse \& Shizgal, 1980; Baker et al. 1982; Livingstone, 1995; French Speaking Society for Parenteral and Enteral Nutrition 1996).

The second method is a composite of various clinical variables that define the continuing course of malnutrition, such as clinical observation: for example, appetite, clinical expression and clinical examination. One of these is the subjective global assessment. This assessment is based on clinical observation, weight change and clinical examination (oedema, dehydration, loss of subcutaneous fat and muscle depletion). This clinical examination requires well-trained physicians or nurses (Detsky et al. 1987).

Reilly et al. (1995) developed a screening list, the nutrition risk score, which was based on weight loss, BMI, food intake and stress factors. The nutrition risk score was validated by comparison with the nutritional risk index (NRI) and with 'clinical appearance', as assessed by a dietitian, as the gold standard. While the nutrition risk score was scored by the dietitian in the present study, it was postulated to be a useful tool for the nursing staff, but no nurses were 
involved in the process of development or in the study. Kovacevich et al. (1997) developed an admission nutrition screening tool for the nursing staff on the basis of diagnosis, nutrition intake history, ideal body weight and weight history. A list of items was to be checked in a fixed order and scored both by nurses and a dietitian; if the score for a particular item indicated that the patient was at risk of malnutrition, further scoring was discontinued. The disadvantage of this, however, is that it does not lead to a complete picture of the risk factors. Moreover, the list was validated with pre-albumin as the gold standard: this is disputable because of the influence of the severity of illness, apart from the nutritional status, on this variable. A number of other screening lists were developed, often based on consensus, but these were not validated (Grindel \& Costello, 1996; Lyne \& Prowse, 1999; Schneider \& Hebutherne, 2000). We agree with Arrowsmith (1999) and Jones (2002), who have stated that an effective tool must meet the following criteria: ease of use; cost-effectiveness; the presence of an action plan and testing for validity; reliability; sensitivity; specificity. Therefore, as advocated by Klein et al. (1997) and Green (1999) it would be worthwhile to have a validated, simple and sensitive screening form available as a basis for nutritional assessment and support and to determine whether a patient is at risk of becoming malnourished.

We consider it self-evident that the nursing staff, based on their professional capacity, have an important role in screening patients at risk of malnutrition and that they should be in a position to do the screening themselves (Evans-Stoner, 1997; Leistra et al. 1999). In the present study, we present a screening list based on a composite of various clinical variables that was developed to be used by nurses, and is not only intended to diagnose malnutrition early, but also to identify patients at risk. The screening list should identify malnutrition to be confirmed by a dietitian; scoring should be easy and rapid for nurses, whether they have been trained in using a screening form or not.

The objective of the nursing nutritional screening form (NNSF) was to develop a screening list that would identify malnutrition and could easily be used by the nursing staff. Relevant questions were: (1) Is there concurrence among nursing staff, clinicians and dietitians when categorizing patients? (2) How many patients were considered malnourished by nurses and confirmed by the dietitians?

\section{Methods}

Based on the most important indicators of nutritional status (weight change, food intake and the nature of the illness, treatment or intervention) (Jeejeebhoy et al. 1990; Ham, 1994; White, 1994), a screening form was developed by a panel of experts, nurses, dietitians and clinicians, in which the following five items were scored as normalmild (A), moderate (B) or severe (C) (Table 1): weight change expressed as \% usual weight; clinical appearance (what the patient looks like, taking into account any recent weight loss); appetite; restrictions on food intake because of problems with chewing and/or swallowing or by occurrence of nausea, vomiting or diarrhoea; stress factors (in second phase: seriousness of the illness, treatment or intervention). If all items are answered with an $\mathrm{A}$, the patient is considered not to be at risk of malnutrition. If a $\mathrm{B}$ or a $\mathrm{C}$ has been entered once or more, the patient is potentially at risk of malnutrition.

The screening form was tested by pairs of nurses, dietitians and clinicians. At the same time, the form was used in five wards for 1 month. The wards were selected on the basis of specialism (surgery, internal medicine, gynaecology and neurology). A nurse completed the NNSF on the day of admission and subsequently on a weekly basis, and reported those patients with a $\mathrm{B}$ or a $\mathrm{C}$ score to the dietitian. The dietitian with her/his professional expertise used a complete nutritional history (anamnestic and dietary history and $24 \mathrm{~h}$ recall), to establish whether the patient is indeed at risk of malnutrition or is actually malnourished (Reilly et al. 1995; Bokhorst-de van der Schueren, 1997).

A patient is considered potentially at risk of malnutrition if the dietitian agrees with a $\mathrm{B}$ or a $\mathrm{C}$ score from the assessment of the nurses. Patients are classified as actually malnourished if a weight loss of $\geq 10 \%$ and an energy intake of $<75 \%$ of that required is established.

In the first test phase (part I), concurrence of the screening form was tested by pairs of nurses, dietitians and clinicians (Fig. 1). The scores of each pair were compared by establishing the extent of concurrence by calculating a Cohen's k using the structure of Landis \& Koch (1977). $\kappa$ indicates the extent of agreement between individual observers while assessing the status of the same person(s). The $\mathrm{B}$ and $\mathrm{C}$ scores on the screening list were combined. Where possible, the same patients were scored six times

Table 1. Items and classification of the risk of malnutrition or actual malnutrition

\begin{tabular}{|c|c|c|c|}
\hline \multirow[b]{2}{*}{ Items } & \multicolumn{3}{|c|}{ Score } \\
\hline & A & $\mathrm{B}$ & C \\
\hline Weight change & $<10 \%$ & $10-20 \%$ & $>20 \%$ \\
\hline Clinical appearance & Good & Moderate & Poor \\
\hline Appetite* $^{*}$ & Good & Moderate & Poor \\
\hline \multicolumn{4}{|l|}{ Food intake } \\
\hline Restrictions while eating & None & Support needed & Starvation \\
\hline Diarrhoea, nausea, vomiting & Little & Regular & Continuous \\
\hline Seriousness of illness, treatment, intervention & Mild & Moderate & Severe \\
\hline
\end{tabular}




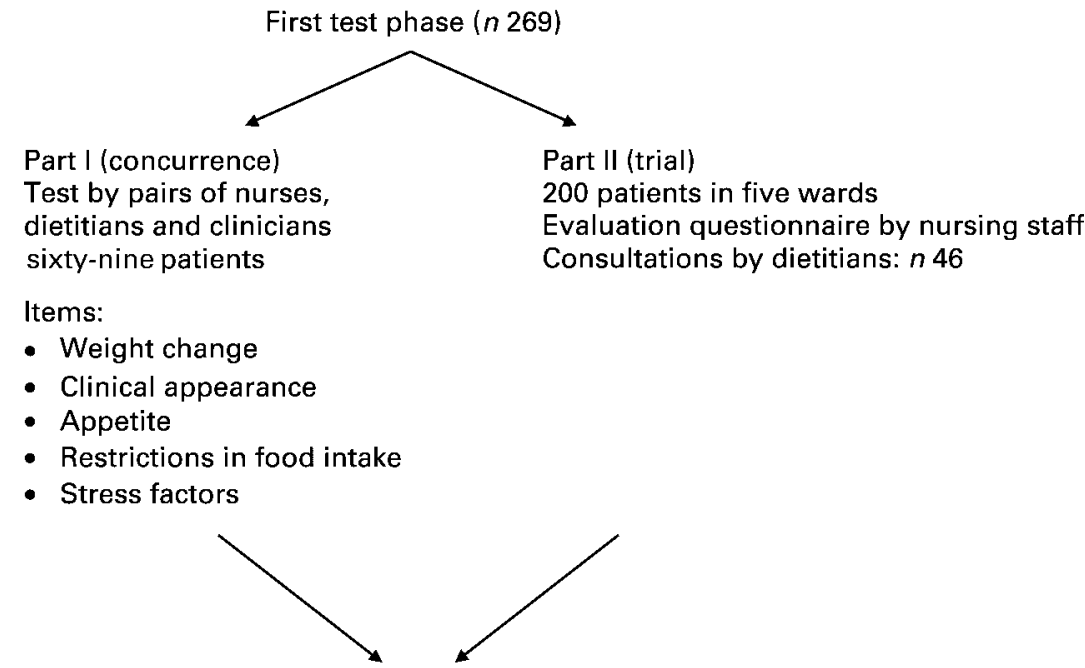

Screening form modified

Second test phase ( $n$ 154)

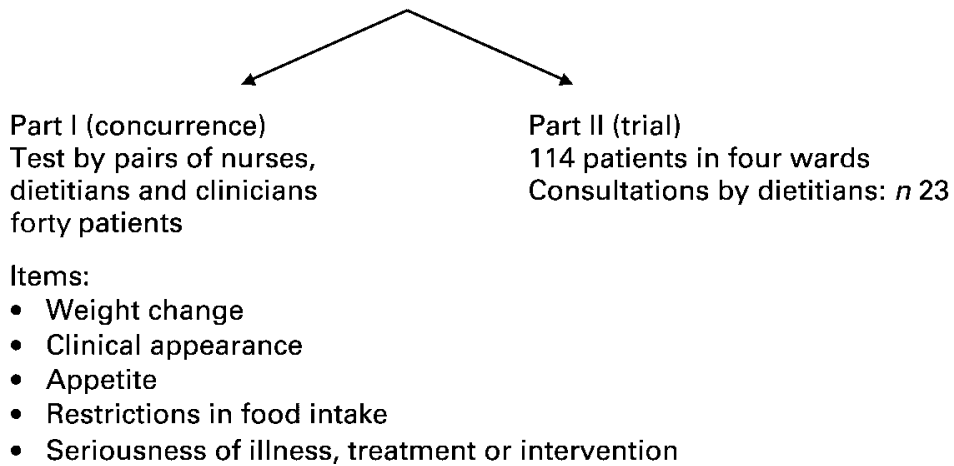

Fig. 1. Phases of the development of the screening form.

on the same day to avoid the possible influence of any changes in the patients' condition.

The NNSF was then used in five wards for 1 month (first test phase, part II). The wards were selected on the basis of specialism (surgery, internal medicine, gynaecology and neurology), differences in length of hospitalization and the seriousness of the patients' illnesses (ranging from routine interventions to lengthy stays in a medium-care department and ward). For all patients with an expected hospital stay of $>5 \mathrm{~d}$, a screening form was completed on the day of admission and subsequently on a weekly basis. Dietitians recorded the consultations that ensued from referrals from the nursing staff based on the NNSF.

After testing the screening form on the wards for 1 month, all nursing staff were requested to complete an evaluation questionnaire. This questionnaire was intended to establish the time required to fill out the NNSF form, the clarity of the questions and of categorizing patients into groups A, $\mathrm{B}$ and $\mathrm{C}$, how well the items on the list referred to nutritional status, and whether or not nurses saw it as their task to identify patients at risk of malnutrition.
As a result of the test for concurrence and the evaluation questionnaire filled in by the nurses, the original screening form was modified (Fig. 1). The 'stress factors' item was changed to 'seriousness of the illness, treatment or intervention'. An explanation of the various items was given on the back of the screening form. In a subsequent second phase of testing the questionnaire, the extent of concurrence was again determined using the modified list (second test phase, part I) and again tested on the wards for 1 month (second test phase, part II).

In twenty-three randomly selected patients, serum albumin concentrations were determined and the NRI was calculated: $\mathrm{NRI}=(1.519 \times$ serum albumin $(\mathrm{g} / \mathrm{l}))+41.7$ (present weight/usual weight). NRI $>100 \cdot 0$ means not malnourished, NRI 97.5-100.0 means mild malnutrition, NRI 83.5-97.5 means moderate malnutrition, NRI $<83.5$ means severe malnutrition (Lyne \& Prowse, 1999).

The BMI (weight $(\mathrm{kg}) /$ height $(\mathrm{m})^{2}$ ) was also calculated for seventy-seven patients and compared with the score for clinical appearance. A BMI $\geq 20.0 \mathrm{~kg} / \mathrm{m}^{2}$ is considered to be normal and is equivalent to a score of $\mathrm{A}$ in the 


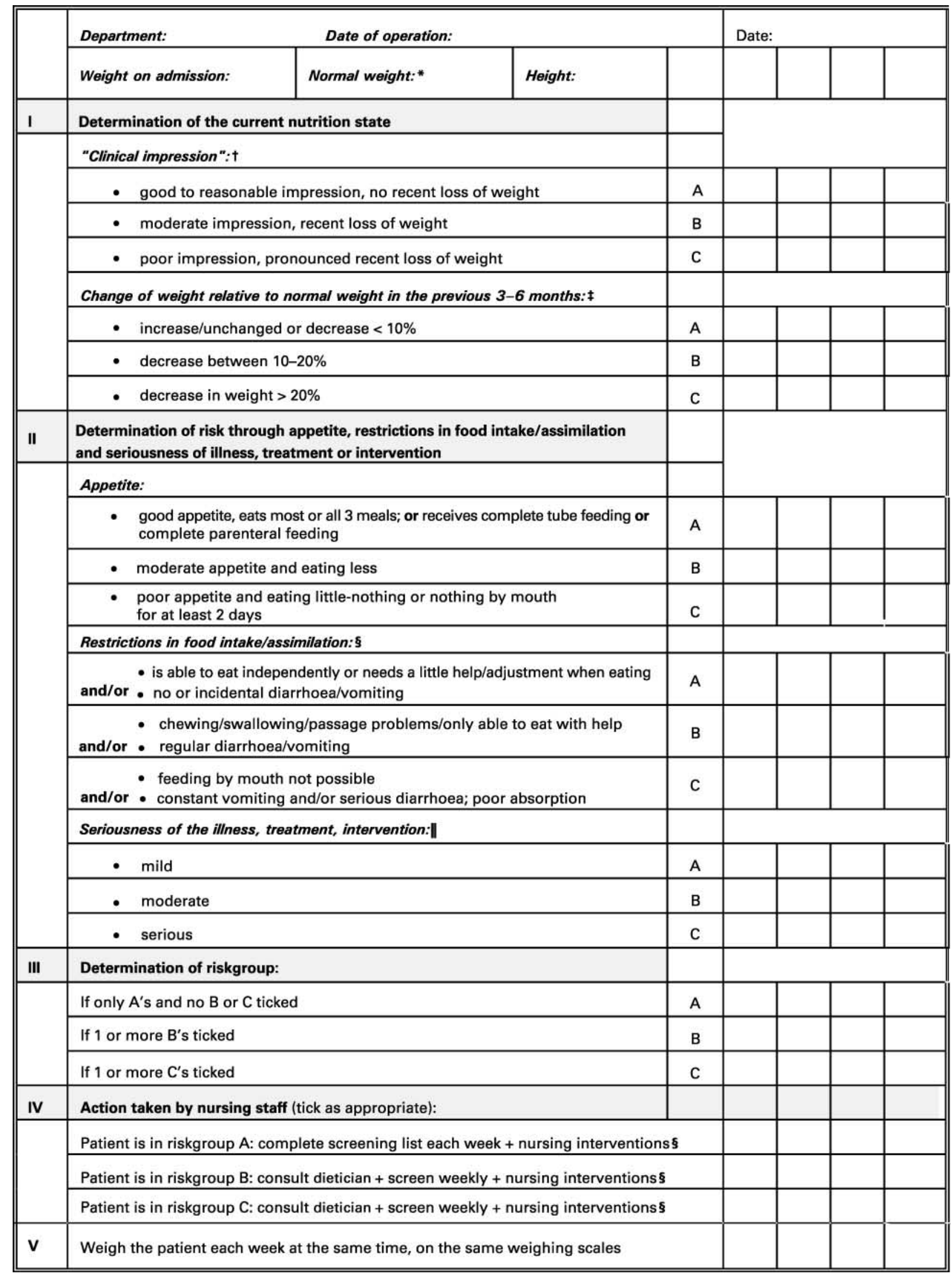


NNSF; a patient with a BMI $18 \cdot 5-20 \cdot 0$ is at risk of malnutrition, equivalent to $\mathrm{B}$; a $\mathrm{BMI}>18.5$ is a $\mathrm{C}$ (Henry, 1990).

The sensitivity of the NNSF was also calculated, with the detailed nutritional anamnestic history by the dietitian as the gold standard.

\section{Results}

\section{Extent of concurrence}

First test phase, part I. The NNSF was completed for sixty-nine patients by pairs of nurses, dietitians and clinicians (Table 2). The extent of concurrence within the pairs was reasonable to good (к $0 \cdot 41-1 \cdot 00)$. There was a reasonable to good concurrence between nursing staff and dietitians for most of the items, but the extent of concurrence between clinicians and nursing staff was less (к $0 \cdot 0-1 \cdot 0$ ), particularly for the interpretation of the stress factors $(0 \cdot 0-0 \cdot 4)$ and risk group $(0 \cdot 0-0 \cdot 2)$.

Second test phase, part I. Once the NNSF had been modified, concurrence was again determined in the second phase among forty patients by pairs of nurses and dietitians (Table 2). The item 'stress factors', which had been changed to 'seriousness of illness, treatment or intervention' led to improvement in concurrence between nurse and dietitian (from 0.0-0.20 to $0 \cdot 21-0 \cdot 40$ ).

\section{Trial period}

First test phase, part II. The NNSF was used for 1 month in five wards with thirty-six beds each. After solving some initial minor problems, completing the form was, generally speaking, performed well. Of 308 patients admitted during that period, $200(65 \%)$ were screened by nursing staff. Thirteen percent of the patients were excluded from screening because the length of their hospitalization was $<5 \mathrm{~d} ; 22 \%$ of the patients were not screened for various reasons, although they were eligible for screening.

Second test phase, part II. In the second phase, the form was used in four wards for 1 month. As a result of internal organizational problems, one ward was unable to participate. A total of 148 patients were admitted of whom $114(77 \%)$ were screened by the nursing staff. Ten percent of the patients were excluded from screening and $13 \%$ of the patients were not screened although they were eligible.

Table 2. Extent of concurrence on the items on the nursing nutritional screening form (NNSF), calculated with $\kappa$ in the first test phase $(n 69)^{*}+$

\begin{tabular}{|c|c|c|c|c|c|c|}
\hline Items on NNSF & Nurse-nurse & Nurse-dietitian & Nurse-clinician & Dietitian-dietitian & Dietitian-clinician & Clinician-clinician \\
\hline Clinical appearance & $0.41-0.60$ & $0.0-0.40 \ddagger$ & $0.41-0.80$ & $0.41-0.60$ & $0.0-0.40$ & $0.61-0.80$ \\
\hline Weight change & $0.81-1.00$ & $0.61-1.00$ & $0.61-1.00$ & $0.81-1.00$ & $0.41-0.80$ & $0.61-0.80$ \\
\hline Restrictions & $0.61-0.80$ & $0.41-0.80$ & $0.41-0.80$ & $0.81-1.00$ & $0.41-0.60$ & $0.41-0.60$ \\
\hline Stress factors & $0.81-1.00 \S$ & $0.0-0.20$ & $0.0-0.40$ & $0.61-0.80$ & $0.21-0.60$ & $0.61-0.80$ \\
\hline Risk group & $0.61-0.80$ & $0.21-0.40$ & $0.0-0.20$ & $0.81-1.00$ & $0.61-0.80$ & $0.61-0.80$ \\
\hline
\end{tabular}

${ }^{*}$ For details of the screening form and procedures, see Figs 1 and 2 and p. 830.

† Scores were structured following Landis \& Koch (1977): <0.00 bad; $0.00-0.20$ poor; $0.21-0.40$ moderate; $0.41-0.60$ reasonable; $0.61-0.80$ good; $0.81-1.00$ excellent.

$\ddagger$ Second test phase $(n$ 40) $0.61-0.80$.

$\S$ Second test phase (seriousness of illness; $n 40) 0.41-0.60$

\|l Second test phase (seriousness of illness; $n$ 40) $0.21-0.40$.

Fig. 2. Nursing nutritional screening form for determining the risk group.

${ }^{*}$ Normal weight (the weight of the patient before his or her illness, i.e. the weight that was usual for this patient).

†Clinical impression (consider: weak handshake, sunken facial expression, dull hair, no interest in surroundings, difficult communicative contact, sick impression; in combination with weight loss).

$\ddagger$ Change of weight (in the past 3-6 months before admission relative to normal weight (\%), e.g. patient with normal weight $>74 \mathrm{~kg}$ has lost $6 \mathrm{~kg}$ in the past 4 weeks, that is $<10 \%(10 \%$ of $74 \mathrm{~kg}=7.4 \mathrm{~kg})$; if the patient has lost more than $18 \mathrm{~kg}$, that is $>20 \%(20 \%=2 \times 10 \%$ of $74 \mathrm{~kg}=14.8 \mathrm{~kg}$ ).

$\S$ Restrictions in food intake and/or assimilation (investigate on the basis of the stated nursing intervention whether anything can be done about the restrictions involved; if it is possible to remove a restriction through nursing intervention, carry out the intervention and, in the event of sucess, report an A). Nursing interventions: (1) appetite stimulating (select food with extra energy and stimulate the patient to eat, ensure that the patient is actually offered the prescribed food, encourage food brought from home if patient is not hungry, do not plan treatment and care at mealtimes, ensure that the patient has clean teeth, ensure that the patient is able to eat quietly, in a comfortable position and in airy surroundings, ensure that the food is presented on a clean plate and at the correct temperature, discuss with the patient the importance of good nutrition and any necessary changes in the feeding pattern, discuss with the patient the effect of a poor nutritional state on the incidence of complications and a possible prolongation of the period of admission, draw up short- and long-term objectives for encouraging good eating habits, give frequent small portions to avoid a feeling of being full); (2) assistance in eating (help the patient to find a good posture during meals, investigate whether the patient is alert and responds well as the time for the meal arrives, help with food preparation (e.g. cutting, opening sachets etc.), offer food and drink regularly and if necessary help the patient with eating and drinking); (3) chewing and/or swallowing and passage problems (discuss soft, minced, pureed or liquidized food with the patient in the event of problems with swallowing, vary the food as much as possible, consider also juices, thick soups, ripe bananas, ice cream, etc., give patients with a dry mouth and/or saliva problems drinks with the meals); (4) vomiting and diarrhoea (give frequent small portions, ensure sufficient fluid intake); (5) preventive intervention (observe good oral care to avoid oral problems, if a patient receives pain medication, plan this in such a way that the patient if free of pain at meal times).

\|Seriousness of the illness, treatment of intervention (consider cardiovascular illness, neurotrauma, fractures, multi-trauma, inflammatory intestinal complaints, burns, cancer, AIDS, (major) surgery, radiotherapy, chemotherapy, decubitus, fever and infections; determine the degree of severity. Score A, B and C, classification of risk from malnutrition or actual malnutrition normal-mild, moderate and severe respectively, see p. 830 for more details. 
Table 3. Referrals by nursing staff to dietitian based on the nursing nutritional screening form during the two trial periods*

\begin{tabular}{|c|c|c|c|c|c|c|c|c|}
\hline \multirow[b]{2}{*}{ Dietitian consultation } & \multicolumn{4}{|c|}{ First test phase ( $n$ 200) } & \multicolumn{4}{|c|}{ Second test phase ( $n$ 114) } \\
\hline & $\begin{array}{l}\text { Patients } \\
\text { (n) }\end{array}$ & $\begin{array}{l}\text { Potentially } \\
\text { at risk }(n)\end{array}$ & $\begin{array}{c}\text { Actual } \\
\text { malnutrition }(n)\end{array}$ & $\begin{array}{l}\text { Not at } \\
\text { risk }(n)\end{array}$ & Patients $(n)$ & $\begin{array}{l}\text { Potentially } \\
\text { at risk }(n)\end{array}$ & $\begin{array}{c}\text { Actual } \\
\text { malnutrition }(n)\end{array}$ & $\begin{array}{l}\text { Not at } \\
\text { risk }(n)\end{array}$ \\
\hline Sooner than expected & 9 & 5 & 4 & - & 14 & 9 & 3 & 2 \\
\hline Additional & 24 & 13 & 4 & 7 & 3 & 2 & 1 & - \\
\hline Expected & 13 & 5 & 7 & 1 & 6 & 2 & 4 & - \\
\hline Total & $46 \dagger$ & $23 \dagger$ & $15 \dagger$ & $8 \dagger$ & $23 \ddagger$ & $13 \ddagger$ & $8 \ddagger$ & $2 \ddagger$ \\
\hline
\end{tabular}

${ }^{*}$ For details of the screening form and procedures, see Figs. 1 and 2 and p. 830.

†23, 11,8 and $4 \%$ for patients, potientially at risk, actual malnutrition and not at risk respectively.

$\ddagger 20,11,7$ and $2 \%$ for patients, potientially at risk, actual malnutrition and not at risk respectively.

\section{Dietitian consultations}

During the trial period, the dietitians recorded the consultations that ensued from referrals from nursing staff on the basis of the NNSF.

First test phase, part II. Forty-six of the 200 patients $(23 \%)$ were seen by the dietitians: thirteen patients had an expected consultation, nine patients had a consultation sooner than expected and twenty-four patients had a consultation as a result of the NNSF score only (Table 3). Of these twenty-four, thirteen were at risk of malnutrition and four patients were actually malnourished. The dietitian evaluated the forty-six patients as: potentially at risk $n 23$, actually malnourished $n 15$, neither at risk nor malnourished $n$ 8. Therefore, thirty-eight patients $(19 \%)$ were identified as potentially at risk of malnutrition $(11 \%)$ or were actually malnourished (8\%) (Table 3$)$.

Second test phase, part II. Of 114 patients, twenty-three $(20 \%)$ were seen by the dietitians as a result of the NNSF. Six patients had an expected consultation, fourteen patients had a consultation sooner than expected and three patients had a consultation as a result of the NNSF score only. The dietitian evaluated these twenty-three patients as: potentially at risk $n 13$, actually malnourished $n 8$, neither at risk nor malnourished $n 2$. Therefore, of the total of twenty-three patients screened using the NNSF form, twenty-one patients $(18 \%)$ were identified as potentially at risk $(11 \%)$ or actually malnourished $(7 \%)$.

\section{Evaluation of the questionnaire}

The trial periods in the wards were evaluated by nursing staff and dietitians using a questionnaire. The time taken to complete the screening list was on average $4 \mathrm{~min}$. Half of the respondents thought that the screening list should be completed once per week. Two-thirds considered the screening list a good reflection of the nutritional status of the patient. Three-quarters of the nurses considered it to be a task for nursing staff. On average, on a scale of 0 to 10 , the usefulness of having such a list was given 6 (Fig. 3). Seventy-seven percent of the evaluated nurses' responses indicated that nurses considered the NNSF useful. In the opinion of the other group of responders, malnutrition could simply be established from clinical experience $(23 \%)$ or these responders did not agree with the principle of the NNSF set-up. As far as the item 'stress factors' was concerned, $42 \%$ of nursing staff still considered it difficult to distinguish between $\mathrm{A}, \mathrm{B}$ or $\mathrm{C}$.

\section{Nutritional risk index and BMI}

The NRI was calculated for twenty-three patients. In nineteen of twenty-three patients $(83 \%)$ the NNSF score corresponded with the NRI (Spearman correlation coefficient $r 0.82, P<0 \cdot 01)$. The BMI was calculated for seventy-eight patients on the day of admission. In sixty-nine patients (88\%), the BMI corresponded with the scored clinical appearance on the NNSF. In seven patients the BMI was $>20.0$ and $\mathrm{a}$ B or a $\mathrm{C}$ was scored. In two patients with a BMI 20.0-18.5 an A was scored for clinical appearance.

\section{Sensitivity}

The sensitivity was determined to be $82.6 \%$ (first phase) and $80.8 \%$ (second phase).

\section{Discussion and conclusion}

The nursing staff had no problems with the time required to complete the NNSF. Neither did they find it a difficult task. Three-quarters of the nursing staff also considered that completing the forms was an important task for nursing staff. The nursing staff were very cooperative about participating in the present research.

We found a large degree of agreement on the screening list items between individual nurses and between

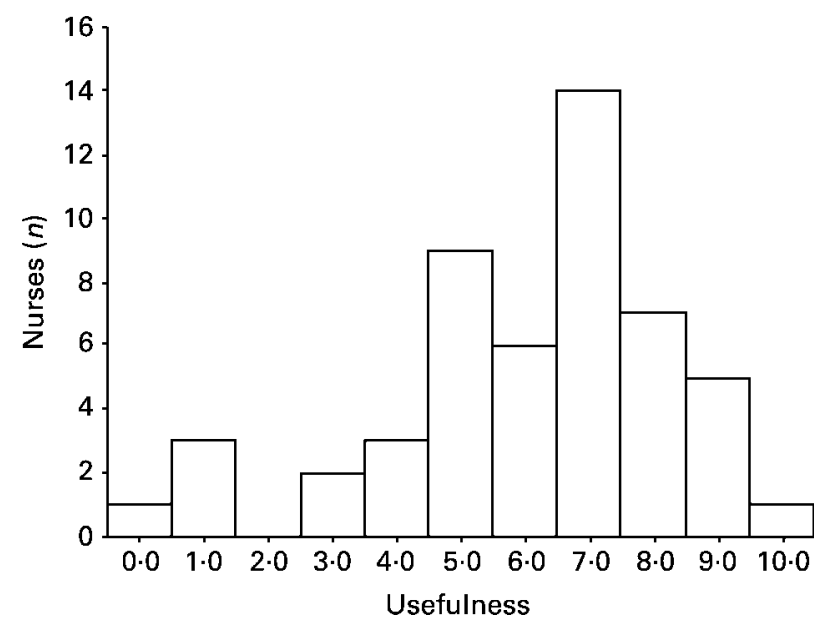

Fig. 3. Usefulness of the nursing nutritional screening form on a scale from 0 (not useful) to 10 (extremely useful) scored by nurses ( $n$ 51; mean score 6.0 (SD 2.3), median value 6.5). For details of the screening form and procedures, see Fig. 2 and p. 830 . 
individual dietitians. In addition, there was considerable agreement between nurses and dietitians. However, it is difficult for these professional groups to establish the seriousness of the illness based on medical standards, as nursing staff indicated in the evaluation and as appeared from the extent of concurrence. Therefore, it is advisable that the nurses, clinicians and dietitians in each ward establish in advance whether an illness can be considered to be mild, moderate or severe.

Concurrence between nursing staff and dietitians was such that more often than not the scores were similar and the same terminology was used. This confirms the findings of Reilly et al. (1995) from their nutrition risk score. In contrast with Reilly's list, clinical appearance was included on our present list because nursing staff often use it as an element in their observation of patients as a reliable item in patient care. In order to facilitate comparison with Reilly's list, BMI was also calculated in patients in the second phase. High levels of agreement were found between BMI and the clinical appearance score on the NNSF.

Although there are two methods of nutritional assessment and the NNSF is a composite of various clinical variables, it is important to compare the NNSF with other studies where other techniques were used as gold standard. Reilly used NRI as standard, which is why we also calculated the NRI for a randomly selected group of patients and compared it with the NNSF; there was indeed a high level of agreement. Kovacevich et al. (1997) applied pre-albumin as the gold standard, but of the twenty-seven patients at nutritional risk, only eleven patients had a low pre-albumin level and sixteen patients a normal level $(P=0 \cdot 03)$. In the present study, we considered the evaluation and opinion of the dietitian the gold standard. Dietitians advised nursing staff and clinicians about the potentially malnourished patients, and the dietitians actually specified particular interventions for those patients who were, in fact, malnourished. Interventions included energy-enriched food, supplementary feeding and drip-feed. We are of the opinion that applying the advice and/or interventions resulting from the well substantiated and clinically relevant nutritional anamnestic history by the dietitians is a good alternative to any non-specific criteria, such as pre-albumin levels. It is not possible to validate a screening list in a different way, since up till now there has been no gold standard for malnutrition.

In both phases of the present study, the sensitivity was high compared with other studies; calculating the specificity was simply not practicable, because then all the patients would have to be seen by the dietitian. The sensitivity corresponds with the findings of Reilly et al. (1995). Assaying sensitivity in these kinds of studies always depends on selection of the standard.

The screening form and the nutritional anamnestic history make it easier for the dietitian to indicate whether a patient is potentially at risk of malnutrition or is actually malnourished. As a result, nutritional advice could be given at an early stage after admission. We were surprised that only $7.0-7.5 \%$ of the patients were malnourished and $11.0-11.5 \%$ were at risk of malnutrition, as these values are much lower than found in the literature (Bistrian et al. 1974; Buzby et al. 1980; Pettigrew et al. 1983; Detsky et al.
1987; Coats et al. 1993; McWhirter \& Pennington, 1994; Reilly et al. 1995; Kovacevich et al. 1997; Naber et al. 1997; Weinsier et al. 1979; Edington et al. 2000). The literature suggests that $20-60 \%$ of hospitalized patients are either malnourished or are in danger of it. Studies carried out between 1974 and 2000 not only showed rather variable values, but also very different variables, which makes it difficult to make a comparison. There was a high correlation between the assessment of the patients' risk of malnutrition using our present list (NNSF) and that of Reilly (nutrition risk score; 1995). A comparison with the list used by Kovacevich et al. (1997) was not possible.

In comparison with the subjective global assessment (Detsky et al. 1987), this form needs no special training for nurses to score the items of the clinical examination. However, all the advantages of the composite method should be retained. In the future, it might be of interest to compare the subjective global assessment with the NNSF.

Our present list is consistent (test-retest), as can be seen from the values in the first and second phases. Our findings agree with the results of the study carried out by Edington et al. (2000). These authors found a prevalence of malnutrition of $20 \%$ based on BMI, weight loss and anthropometry. However, the authors also reported that $53 \%$ of their eligible patients were not included in the study. In our present study, 22 and $13 \%$ of the patients were not screened in the first and second phases respectively. In practice, it is extremely difficult to implement any kind of screening so that no patients are omitted. Furthermore, the number of patients not correctly scored as malnourished was low and decreased from 5 to $2 \%$ (Table 3 ).

In our present study, approximately $20 \%$ (19\% in the first phase and $18 \%$ in the second phase) of hospitalized patients were identified as potentially at risk of malnutrition or were actually malnourished. As a consequence, this led to a 52 and $13 \%$ increase in the number of dietitian consultations in the first and second phase of the trial respectively (Table 3). As a first approximation, this will cause an increase in the number of dietitian consultations on an annual basis when, as expected, $20 \%$ of patients are at risk of malnutrition.

We consider it very important when introducing this kind of form that the consequences are clear and accepted by the different professional groups beforehand. If, on the basis of the screening form, a nurse concludes that the patient is at risk of malnutrition, he/she should be able to request a dietitian consultation directly. In addition, the dietitian must be free to give feedback and nutritional advice to the clinician and nursing staff in attendance. On the basis of their own expertise, these professional groups must make their own assessment and deviate from the recommendations only if there are well-founded reasons for doing so. This means that on implementation of this kind of form, it must be stressed that patient nutrition is a multidisciplinary responsibility with a joint approach.

To summarize, this screening form for determining the risk of malnutrition in patients is a useful instrument. The NNSF was developed and tested by nurses, dietitians and clinicians. Therefore, there was a great willingness to 
use the list. The NNSF is easy for the nursing staff to use and they considered it part of their work. It requires only a small amount of time; there are no extra costs. By implementing the NNSF, malnourished patients or patients at risk of malnutrition can be traced at an early stage of their hospitalization.

\section{Acknowledgements}

We are indebted to I. van der Tweel for assistance with the statistical analysis and for her critical review. We would also like to thank the nursing staff for their help and cooperation. We wish to express our gratitude to Professor L. M. A. Akkermans for his helpful comments and review.

\section{References}

Arrowsmith H (1999) A critical evaluation of the use of nutrition screening tools by nurses. Br J Nurs 22, 1483-1490.

Baker JP, Detsky AS, Wesson DE, et al. (1982) Nutritional assessment - A comparison of clinical judgment and objective measurements. N Engl J Med 306, 969-972.

Bistrian BR, Blackburn GL, Hallowell E \& Heddle R (1974) Protein status of general surgical patients. JAMA 239, 858-860.

Blackburn G \& Thornton P (1979) Nutritional assessment of the hospitalised patient. Med Clin North Am 63, 1103-1115.

Buzby GP, Mullen JL, Matthews DC, Hobbs CL \& Rosato EF (1980) Prognostic Nutritional Index in gastrointestinal surgery. Am J Surg 139, 160-167.

Coats KG, Morgan SL, Bartolucci AS \& Weinsier RL (1993) Hospital associated malnutrition: a reevaluation 12 years later. $J$ Am Diet Assoc 93, 27-33.

Collins JP, McCarthy ID \& Hill GL (1979) Assessment of protein nutrition in surgical patients - the value of anthropometrics. Am J Clin Nutr 32, 1527-1530.

Detsky AS, McLaughlin JR, Baker JP, et al. (1987) What is subjective global assessment of nutritional status? J Parenter Enteral Nutr 11, 8-13.

Edes TE (1991) Nutrition support of critically ill patients. Postgrad Med 5, 193-200.

Edington J, Boorman J, Durrant ER, et al. (2000) Prevalence of malnutrition on admission to four hospitals in England. Clin Nutr 19, 191-195.

Evans-Stoner N (1997) Nutrition assessment. A practical approach. Nurs Clin North Am 4, 637-650.

Forse RA \& Shizgal HM (1980) The assessment of malnutrition. Surgery 88, 17-24.

French Speaking Society for Parenteral and Enteral Nutrition (1996) Perioperative artificial nutrition in elective adult surgery. Clin Nutr 15, 223-229.

Green CJ (1999) Existence, causes and consequences of diseaserelated malnutrition in the hospital and the community, and clinical and financial benefits of nutritional intervention. Clin Nutr 18, Suppl. 2, 3-28.

Grindel GC \& Costello MC (1996) Nutrition screening: an essential assessment parameter. $J$ Acad Med-Surg Nurs 3, 145-156.

Halsted ChH (2001) Malnutrition and nutritional assessment. In Harrison's Principles of Internal Medicine, pp. 455-461 [E Braunwald, AS Fauci, DL Kasper, SL Hauser, DL Longo and JL Jameson, editors]. New York, NY: McGraw-Hill Inc.

Ham RJ (1994) The signs and symptoms of poor nutritional status. Prim Care 1, 33-54.

Henry CJK (1990) Body mass index and the limits of human survival. Eur J Clin Nutr 44, 329-335.
Jeejeebhoy KN, Detsky AS \& Baker JP (1990) Assessment of nutritional status. J Parenter Enteral Nutr 14, 193-196.

Jones JM (2002) The methodology of nutritional screening and assessment tools. J Hum Nutr Diet 15, 59-71.

Jong PCM de, Wesdorp RIC, Volovics A, Rouffart M, Greep JM \& Soeters PB (1985) The value of objective measurements to select patients who are malnourished. Clin Nutr 4, 61-66.

Kern K \& Norton J (1988) Cancer cachexia. J Parenter Enteral Nutr 12, 286-295.

Klein S, Kinney J, Jeejeebhoy KN, et al. (1997) Nutrition support in clinical practice: review of published data and recommendations for future research directions. Am J Clin Nutr 66, $683-706$.

Kovacevich DS, Boney AR, Braunschweig CL, Perez A \& Stevens M (1997) Nutrition Risk Classification: A reproducible and valid tool for nurses. Nutr Clin Pract 12, 20-25.

Landis RJ \& Koch GG (1977) The measurement of observer agreement for categorical data. Biometrics 33, 159-174.

Leistra E, Liefhebber S, Geomini M \& Hens H (1999) Job Description for Nurses. Maarssen, The Netherlands: Elsevier/De Tijdstroom; Netherlands Centre for Excellence in Nursing.

Livingstone MBE (1995) Assessment of food intakes: are we measuring what people eat? Br J Biomed Sci 52, 58-67.

Lyne PA \& Prowse MA (1999) Methodological issues in the development and use of instruments to assess patient nutritional status or the level of risk of nutritional compromise. $J$ Adv Nurs 4, 835-842.

Markou SA, Kalfarentzos F \& Androulakis J (1993) Prediction of nutrition-associated complications using clinical nutritional assessment: an objective medical decision making approach. Theor Surg 8, 84-89.

McWhirter JP \& Pennington CR (1994) Incidence and recognition of malnutrition in hospital. Br Med J 308, 945-948.

Meyenfeldt MF von, Meijerink WJHJ, Rouflart MMJ, Builmaassen MTHJ \& Soeters PB (1992) Perioperative nutritional support: a randomised clinical trial. Clin Nutr 11, $180-186$.

Naber THJ, Schermer T, de Bree A, et al. (1997) Prevalence of malnutrition in nonsurgical hospitalized patients and its association with disease complications. Am J Clin Nutr 66, 1232-1239.

Pettigrew RA, Charlesworth PM, Farmilo RW \& Hill GL (1983) Assessment of nutritional depletion and immune competence: A comparison of clinical examination and objective measurements. J Parenter Enteral Nutr 8, 21-24.

Reilly HM, Martineau JK, Moran A \& Kennedy H (1995) Nutritional screening. Evaluation and implementation of a simple Nutrition Risk Score. Clin Nutr 14, 269-273.

Schneider SM \& Hebutherne X (2000) Use of nutritional scores to predict clinical outcomes in chronic diseases. Nutr Rev 2, 31-38.

Symreng T, Anderberg B, Kågedal B, Schildt AB \& Sjödahl R (1983) Nutritional assessment and clinical course in 112 elective surgical patients. Acta Chir Scand 149, 657-662.

Van Bokhorst-de van der Schueren MAE, van Leeuwen PM, Sauerwein HP, Kuik DJ, Snow GB \& Quak JJ (1997) Assessment of malnutrition parameters in head and neck cancer and their relation to postoperative complications. Head Neck 19, 419-425.

Weinsier RL, Edie PH, Hunker RN, Krumdieck CL \& Butterworth CE (1979) Hospital nutrition: a prospective evaluation of general medical patients during the course of hospitalisation. Am J Clin Nutr 32, 418-426.

White JV (1994) Risk factors for poor nutritional status. Prim Care 1, 19-32. 